Journal of Southeast Asian

\title{
Revealing the Resistant Capital of Cambodian Youth: Using Photovoice as a Tool for Advocacy and Policy Change
}

Erin L. Papa

Rhode Island College, epapa@ric.edu

Follow this and additional works at: https://docs.lib.purdue.edu/jsaaea

Part of the Bilingual, Multilingual, and Multicultural Education Commons

\section{Recommended Citation}

Papa, Erin L. (2019) "Revealing the Resistant Capital of Cambodian Youth: Using Photovoice as a Tool for Advocacy and Policy Change," Journal of Southeast Asian American Education and Advancement. Vol. 14 : Iss. 1, Article 13.

DOI: $10.7771 / 2153-8999.1182$

Available at: https://docs.lib.purdue.edu/jsaaea/vol14/iss1/13

This document has been made available through Purdue e-Pubs, a service of the Purdue University Libraries. Please contact epubs@purdue.edu for additional information.

This is an Open Access journal. This means that it uses a funding model that does not charge readers or their institutions for access. Readers may freely read, download, copy, distribute, print, search, or link to the full texts of articles. This journal is covered under the CC BY-NC-ND license. 


\title{
ISAAEA Journal of Southeast Asian American
Education and Advancement
}

Vol. 14 Iss. 1 (2019)

WWW.JSAAEA.org

\section{Revealing the Resistant Capital of Cambodian Youth: Using Photovoice as a Tool for Advocacy and Policy Change}

\author{
Erin L. Papa \\ Rhode Island College
}

\begin{abstract}
This paper explores the use of Photovoice as a tool for uncovering or developing resistant capital (Yosso, 2005) with youth for language education policy change. Using data from a Youth Participatory Action Research (YPAR) study on the relationships and tensions among the home, community, and school linguistic and social practices of emergent bilingual Cambodian youth in an urban district in the northeastern United States, I argue that the development of resistant capital depends on various contextual and demographic factors. The Cambodian youth, who have been educated in a recursive bilingual environment (García, 2009) and are involved in a youth-led community organization with a social justice focus demonstrate resistant capital, which was likely fortified through their work there. Suggestions are made for using Photovoice in schools to develop resistant capital for policy change with languageminoritized youth.
\end{abstract}

Keywords: Critical race theory, Community cultural wealth, Photovoice, Cambodian youth, Language-minoritized.

\footnotetext{
(c)

SDRERIIGHISRESERNEDR Readers are free to copy, display, and distribute this article, as long as the work is attributed to the author(s) and the Journal of Southeast Asian American Education \& Advancement, it is distributed for non-commercial purposes only, and no alteration or transformation is made in the work. More details of this Creative Commons license are available at http://creativecommons.org/licenses/by-nc-nd/3.0/. All other uses must be approved by the author(s) or JSAAEA . Journal of Southeast Asian American Education \& Advancement, Vol. 14. Iss. 1. (2019) ISSN: 2153-8999
} 


\section{Introduction}

Cambodians first came to the United States as refugees in the 1980s after escaping genocide, poverty, starvation, and violence in their home country and spending time living in refugee camps (Smith-Hefner, 1993). Current research on Cambodian youth is limited; the literature on Cambodian youth have focused on intergenerational conflict, criminalization of male youth, and the role of ethnic and gender identity in education (Chhuon \& Hudley, 2010; Chhuon, 2014; Ngo \& Lee, 2007; Tang \& Kao, 2012; Wallitt, 2008). This study adds to the existing literature by shifting the focus from a deficit- to an assets-based view by engaging Cambodian youth as coresearchers in a Photovoice process to bring to light their community cultural wealth (Yosso, 2005) and to use this knowledge for advocacy and policy change. Photovoice is a participatory action research (PAR) strategy through which participants use photography to first identify, document, and critically analyze an issue, and to then develop an advocacy response (Wang \& Burris, 1997). I describe the overall study and policy recommendations of the youth in another publication (Papa, 2018). In this article, I explore the presence and potential for development of resistant capital (Yosso, 2005), one form of community cultural wealth displayed by the co-researchers, using Photovoice, and argue that the development of resistant capital varies based on various contextual and demographic factors.

Using a Critical Race Theory (CRT) framework and Photovoice methodology (Wang \& Burris, 1997; Wang, 2006), I engaged Cambodian and Guatemalan youth (Papa, 2018) as coresearchers using photography and discussion to address the following research questions:

1. What are the home and community linguistic and social practices of Cambodian and Guatemalan youth, and how are they related to, or in tension with, school practices?

2. What stories do these youth tell using Photovoice about their experience as bilingual individuals at home, in the community, and at school?

3. What recommendations do youth make based on their school learning experiences and how might their recommendations be put into practice?

For the purpose of this article, I focus on the portion of the study conducted with five secondgeneration Cambodian American youth (born in the United States to refugee parents) in a youthled community organization in Eagle City. After the conclusion of the study, the youth presented their photos and distributed their educational recommendations at a photo gallery walk at City Hall. The data indicate that the Cambodian co-researchers had previously developed resistant capital (Yosso, 2005) through their training and work as youth organizers. The paper concludes with suggestions for using Photovoice to highlight and develop resistant capital for policy change with language-minoritized youth.

\section{Theoretical Framework: Critical Race Theory}

Critical race theory (CRT) (Delgado \& Stefancic, 2001; Yosso, 2005) is commonly used by researchers conducting participatory action research (PAR) projects, as a lens through which to analyze power relations through the intersection of race and racism with gender, class, language, sexuality, and other forms of subordination (Cammarota and Fine, 2008). CRT challenges the dominant ideologies that are embedded in educational and social practice by building on the 
knowledge of marginalized communities to deconstruct oppressive conditions, thus empowering these communities to advocate for social justice. Using Tara Yosso's (2005) CRT-inspired framework of community cultural wealth, this study brings to light the strengths of the youth coresearchers.

\section{Community Cultural Wealth}

Yosso's (2005) model of community cultural wealth moves beyond Bourdieusian interpretations of cultural capital, which see White, middle class culture as the "standard" by which all other cultures are judged (Bourdieu \& Passeron, 1977; Bourdieu, 1986), by instead focusing on the wealth inherent in communities of color. Yosso (2005) describes community cultural wealth as "an array of knowledge, skills, abilities and contacts possessed and utilized by Communities of Color to survive and resist macro and micro-forms of oppression" (p. 77). The various forms of capital, which are dynamic processes that build upon one another, include aspirational, linguistic, familial, social, navigational, and resistant capital. For example, middle class students may have parents with graduate degrees, who pass along the tools, skills, and strategies that are valued in the educational system. Conversely, Cambodian youth may utilize their Khmer and English skills to interpret for a parent at the doctor's office, use navigational skills to travel on public transportation, and work full-time after school to support the family. While these are valuable skills to the students and their families, they are skills not often valued in school. This CRT-inspired model provides a frame through which to examine the home and community linguistic and social practices of Cambodian youth and their relationships and tensions with such practices in Eagle City Public School (ECPS). In this particular article I focus on resistant capital, which is grounded in the Freirean (1970) notion of critical consciousness, as an essential form of capital for advocacy and policy change.

\section{Resistant Capital}

Yosso (2005) describes resistant capital as "those knowledges and skills fostered through oppositional behavior that challenges inequality" which she further explains is "grounded in the legacy of resistance to subordination exhibited by Communities of Color" (p. 80). This form of capital is often intertwined with other forms of community cultural wealth, including aspirational, linguistic, familial, social, and navigational capital (Yosso, 2005; Yosso \& García, 2007). The Cambodian youth demonstrated their resistant capital in their focus on the importance of "maintaining and passing on the multiple dimensions of community cultural wealth" (Yosso, 2005, p. 80) to maintain and develop the knowledge base in the Southeast Asian community. Their resistance also took on a transformative form, in that the youth recognized "the structural nature of oppression" and demonstrated the "motivation to work toward social and racial justice" using their "cultural knowledge of the structures of racism and motivation to transform such oppressive structures" (Yosso, 2005, p. 81). Yosso (2005) calls this transformative resistant capital, which is similar to what Satya Mohanty (2000) calls epistemic privilege. The Cambodian co-researchers developed this transformative resistant capital in their work and development as youth organizers, but felt that the public school system they attended did not provide the opportunity or space for the expansion or development of this critical consciousness. In the next section I describe in further detail the research context along with my positionality in the study. 


\section{Methodology}

\section{Research Context}

This study took place in Eagle City, a medium-sized city in the northeastern United States, during the spring of 2015. Eagle City's population has shifted over the past couple of decades to one in which the majority of residents are people of color, yet the city is still very much racially and economically segregated. In Eagle City Public Schools (ECPS), Cambodian youth make up the largest group within the aggregate "Asian" racial category. However, due to the essentializing (Delgado \& Stefancic, 2001) of groups into broad racial categories, their experiences and needs typically go unnoticed. ECPS is a medium-sized urban New England district serving 23,867 students in the 2015-2016 academic year with 79\% eligible for subsidized lunch and a racial distribution of 64\% Hispanic, 17\% African American, 9\% White, 5\% Asian, 4\% Multiracial, and $1 \%$ Native American. ${ }^{1}$ ECPS does not report data by ethnicity, however, the U.S. Census Bureau's 2006-2010 American Community Survey (ACS) shows that Cambodians, as the largest Asian group, made up 30\% of the Asian population. The 2006-2010 ACS shows that 947 Cambodians aged three years or older were enrolled in school levels PK-12 in Eagle City (U.S. Census Bureau, 2006-2010). Looking at available data on the 2010-2014 ACS, we see that the Cambodian population remained steady with approximately 3,300 EC residents, making this study particularly pertinent to ECPS.

The Cambodian youth co-researchers are all active in Eagle City Youth Action (ECYA), a youth-led organization founded in the early 2000s as a response to deportations in the Southeast Asian community with a focus on addressing state, street, and interpersonal violence. They are all part of the organizing committee within ECYA, which includes 6-8 high school-aged youth, as well as an older youth mentor/facilitator. At the time of the study, all of the organizing committee members were Cambodian American, as this is the largest Southeast Asian group in the community, but ECYA welcomes youth of all backgrounds who wish to develop knowledge and skills for addressing issues affecting their community. The group meets twice weekly throughout the year. ECYA provides the space and training necessary for the youth organizers to critically examine their own experiences and history, as well as the social and political forces affecting their community today. The process of developing resistant capital can be described as what Ginwright and Cammarota (2007) call critical civic praxis, "a process that develops critical consciousness and builds the capacity for young people to respond to and change oppressive conditions in their environment" (p. 699). They suggest that community organizations, such as ECYA, facilitate and sustain this process by creating ties with adult community members, by challenging negative stereotypes about urban youth in public policy, and by building "collective interests through critical consciousness among urban youth" (p. 706). ECYA develops critical consciousness by providing leadership training to new youth members that includes sessions on the "-isms," that is, racism, sexism, heterosexism; Southeast Asian history; immigration; and the history of the police; among other related topics. The youth learn workshop facilitation techniques, practicing first within ECYA, and then as members of the organizing committee going out to other community organizations and spaces to facilitate workshops. The youth organizers also work in coalition with other activist organizations in Eagle City to develop and lead campaigns to address issues that affect the broader community, such as police violence, deportation and immigrant rights, and LGBTQ rights, where the youth gain experience working with a diverse group of adults and 
navigating the political process. By situating experience and community wellbeing at the core of these campaigns, the youth develop resistant capital.

\section{Research Design}

I chose to use Photovoice, a PAR methodology, as it was my aim to avoid further marginalization of the participants in my research. By engaging youth in the project as co-researchers, I aimed to promote the worth, dignity, and development of individuals within and cultures and languages of the Cambodian community in ECPS. PAR "embodies the values of critical, critical race, and feminist theories of knowledge production" (Nygreen, 2009-2010, p. 16) and as such involves the collaboration of researchers and participants in the research process with the aim of social transformation. Photovoice combines Freireian notions of critical consciousness with feminist theory and the social change aim of documentary photography (Wang \& Burris, 1997; Wang, 2006). Originally Photovoice was developed by Wang and Burris (1997) to address community public health concerns by (a) enabling people to use photography to document and reflect upon the strengths and concerns of their community; (b) to promote critical dialogue about these issues through small and large group discussion of their photos; and (c) to reach policymakers. Using CRT in combination with Photovoice, I worked with Cambodian youth to bring their voices and concerns to the attention of policymakers. Upon completion of the study, I analyzed the data using Yosso's (2005) CRT model of community cultural wealth to further highlight the oftentimes hidden community strengths.

\section{Participant Recruitment}

In early 2015, I recruited participants using purposive sampling (Patton, 2002) in order to include multiple perspectives on linguistic and social practices in the home and community. I negotiated with the youth prior to beginning the research to agree upon what each of us wants out of the research (Herr \& Anderson, 2015; Nygreen, 2009-2010). As a doctoral student, I needed to complete a dissertation, but as an activist researcher, I was committed to working in collaboration with youth to identify linguistic strengths and concerns in their respective communities with the intent to make change. The participants in this study were five Cambodian youth aged 14-21 who attend or had attended ECPS for a minimum of one semester. I recruited the youth participants through Eagle City Youth Action (ECYA), a youth-led organization focused on addressing issues in the Southeast Asian community. I was connected to one of the co-directors originally through a former colleague, who is a community activist. Establishing the connection to the organization through a known and trusted connection as well as by volunteering there helped me to establish trust with the youth prior to the start of the study.

\section{Researcher Positionality}

As an outsider to the Eagle City community, and more specifically to the Cambodian community, I tried to remain cognizant of and upfront about the power and privilege that I carry in my interactions with the youth. Greenwood \& Levin (2007) have called this the role of the "friendly outsider" (p. 125). Herr and Anderson (2015) call this outsider action research, and specify that in this case I was an "outsider in collaboration with insiders." They emphasize that the "issue of what each stakeholder wants out of the research needs to be negotiated carefully if reciprocity is to be 
achieved" (p. 39). In keeping with the tenets of my theoretical framework, I also reflected upon my racial, gender, educational, economic, and other positioning that I bring to the study.

I am a White woman from a middle-class suburban background. I have lived most of my life in the state, not more than a 40-minute drive from Eagle City. My family is well established in the state, with many property and small business owners included. I have been very lucky to pursue higher education and advanced degrees without financial struggle. My privilege has allowed me to travel around the world, in some cases to study (Germany, China, Guatemala), some to work (Germany, Australia, China), and some to explore either on my own or in visiting friends. In my professional life, I have worked in language education in some capacity, either as an ESL teacher or a language/international programs administrator, for 16 years. Through my experiences, I have found that the rich linguistic and cultural diversity present in our schools is typically overlooked and underdeveloped.

In my work at the higher education level, I was always drawn to help students whose home languages had been lost or underdeveloped through English-medium education in the United States to develop pride in their languages. Oftentimes these same students struggled in writing scholarship application essays in English as college students, likely due to the low level of literacy in their home languages. As I became more involved in a project aimed at changing language education in K-12 to include dual language immersion programs in the languages needed by employers, I wanted to focus my dissertation research on issues identified by youth. Recognizing that Cambodians made up significant portions of the larger "Asian" racial group, and that their families experienced additional challenges in adapting to life in the United States due to their history of forced migration to the United States due to state-supported violence and genocide, I chose to work with youth in this community.

\section{Data Collection and Analysis}

I used Wang's nine-step Photovoice strategy (2006) to carry out this study. Prior to beginning the Photovoice process, I asked each participant to complete a demographic and language use survey, which I adapted for Cambodian youth from Montrul's (2012) and Gignoux's (2009) surveys available on the National Heritage Language Resource Center (NHLRC) website. The survey collected information on language use and ability and family educational background. As a point of reference, Table 1 shows basic demographic and language information of the co-researchers, as reported by the youth. Although not all indicated a third language on the questionnaire, I include third languages here based on what I learned in our conversations.

Table 1. Youth co-researchers demographic \& language use information.

\begin{tabular}{lccccc}
\hline Name & Gender & Age & $\begin{array}{c}\text { Primary } \\
\text { Language }\end{array}$ & $\begin{array}{c}\text { Secondary } \\
\text { Language }\end{array}$ & Third Language \\
\hline Linda & F & 15 & English & Khmer & Spanish \\
Foster K. & F & 15 & English & Khmer & Spanish \\
Drake & M & 16 & English & Khmer & French \\
Reptar & M & 21 & English & Khmer & \\
Ace & F & 14 & English & Khmer & Spanish \\
\hline
\end{tabular}


For most of the Cambodian youth, third languages are those studied in high school, although for Ace, Spanish is both a language of the home (as her father is from Guatemala) and one studied in school. All indicated that they use at least two languages at home, indicated here as the primary and secondary languages, in terms of their level of comfort and frequency of use. All indicated on the questionnaire that Khmer was their primary language of use from age 0-5, but that English became dominant thereafter. This is reflective of the overwhelming power of the English language in the United States

Upon completion of the surveys, I engaged the youth in a discussion about their language use at home, in the community, and at school to establish a baseline from which to begin introducing Photovoice. I include this below within Wang's Photovoice strategy (2006):

(1) Administer language use survey and discuss responses;

(2) introduce Photovoice methodology and facilitate a discussion about cameras, power, and ethics;

(3) youth take photos of primary language use in the home and community, and then write about and discuss them using these guiding questions following Wang's SHOWeD mnemonic:

(a) What do we see here?

(b) What is really happening here?

(c) How does it relate to our lives?

(d) Why does this situation, concern or strength exist?

(e) What can we do about it? (Wang, 2006, p. 151);

(4) repeat step (3) for secondary language use and then again for other language use or clarifying photos;

(5) determine audience for the photo gallery walk;

(6) discuss themes identified in the photos and identify priorities for the development of a policy recommendation document;

(7) distribute policy document to policymakers at gallery walk.

The Cambodian youth co-researchers followed the photography schedule, but struggled with remembering to use the digital cameras during the first round of photography. Thereafter, the group decided that using their Smartphones would work better for most, although Reptar chose to use ECYA's professional-quality camera, and Linda, who did not have a Smartphone, kept one of the digital cameras provided. They also requested that we create a Facebook group, where I could send reminders and they could post photos, which would, in turn, remind the others to take photos. We also created a private, shared Google Drive folder for the collection of photos, so that they could upload them and I could print them in their original, high-resolution format, and we could easily view them during our meetings. This group completed three rounds of photography, first focusing on English language/their "American side," then on Khmer language/Cambodian culture, and finally taking clarifying photos that they thought would make a greater impact on policymakers. In this case, each of the youth presented each of their photos to the group, explaining why they took it, prior to then choosing at least three to write about following the SHOWeD questions. When planning the gallery walk, the group immediately suggested public places, where they might have the greatest visibility, finally agreeing on City Hall. I then contacted the Mayor's Office and was able to secure City Hall as a venue through its arts and culture department. In developing the policy recommendations document with the Cambodian youth, they immediately 
began to discuss themes that had emerged from their photos, including the need for language classes reflecting the demographics of the community, ethnic studies classes, and translation services. They then chose to create a shared Google Document with a thesis statement preceding and research to support the three recommendations. When we ran out of time to complete this during our regular session, Reptar suggested that we meet over Google Hangout on the weekend to complete the document, which the group agreed to do. I joined them as facilitator, also helping to locate research to support their recommendations and formatting the final document for distribution at the final gallery walk.

After our work together, I analyzed the data, which include the demographic and language use surveys, recorded group discussions (using the iPhone Voice Memos application) and transcripts, field notes, photos, and written responses to the photos using Yosso's (2005) community cultural wealth framework. I did not record conversations at the final gallery walk at City Hall due to the challenge in obtaining permission from all attendees, but I did record one final conversation with the group the following week when we met to reflect upon the gallery walk and overall study. What emerged from the data was the strong demonstration of resistant capital (For more on their demonstration of other forms of capital, see Papa, 2017). In the next section, I present illustrative examples of resistant capital demonstrated by the youth co-researchers.

\section{Findings}

In this section, I present an analysis of photos and excerpts from my conversations with my coresearchers where they exhibited resistant capital or a potential for its development. The data indicate that a combination of contextual, experiential, and demographic factors, shown in Table 2 , has influenced their development of resistant capital.

Table 2. Factors influencing resistant capital.

\begin{tabular}{ll}
\hline Language & $\begin{array}{l}\text { English dominant (read/write/speak) with Khmer oral proficiency; } \\
\text { Learning Spanish or French in school; Desire for bilingual } \\
\text { education } \\
\text { Consistent formal education; English monolingual education }\end{array}$ \\
$\begin{array}{l}\text { Education } \\
\text { Family Background } \\
\text { Immigration Status }\end{array}$ & $\begin{array}{l}\text { Born in the United States to refugee parents } \\
\text { United States Citizens }\end{array}$ \\
Basic Needs & $\begin{array}{l}\text { Basic needs met, although most parents work low-paying jobs } \\
\text { Immediate family in the United States }\end{array}$ \\
Choice & Feeling of choice to participate in study (community setting) \\
Experience & Leadership training through ECYA \\
\hline
\end{tabular}

As noted in Table 1, as well as here in the first row of Table 2, all co-researchers are to some degree bilingual, and in most cases are becoming trilingual. The youth co-researchers can be considered refugee-background, in that they or their parents were forced to leave their home countries due to unstable and violent circumstances (Feuerherm \& Ramanathan, 2016, p. 5). They have also experienced a largely monolingual education that privileged the dominant language of government and those in power over those of their respective homes and communities. Despite this, or perhaps because of it, the youth called for bilingual education as a way to (re)claim their Khmer, which they felt had been lost due to their English-only education (I examine this in greater detail later in this article.). This desire was reflective of their resistant capital, developed through 
a lifetime of experience in a society and educational system that positioned them as other. At first, they envisioned Khmer being taught at the high school level, as in their own experience in ECPS, this is when languages are taught. After I pushed them to think about when they would ideally have started learning in Khmer, and also introduced them to different language program models, the Cambodian co-researchers envisioned a plan for eventually developing a Khmer-English dual language immersion program starting in Kindergarten in cooperation with monks in the local Cambodian Buddhist temples and with the few ECPS faculty who are literate in Khmer.

Immigration status may affect the development or demonstration of resistant capital. Since the Cambodian co-researchers are U.S. Citizens, they are free from worry about being deported (although deportation is an issue in the Cambodian community among those who came as refugees and are Permanent Residents of the United States, but have not obtained citizenship). This feeling of security provides the space within which to exert their agency and to exhibit resistant capital. The co-researchers were used to me participating in their meetings along with other adults from the community. This level of comfort allowed them to be open and honest in sharing their ideas and experiences.

In their experience as youth organizers at ECYA, the Cambodian co-researchers were provided the space to exert their agency in identifying issues in their community and provided the leadership skills to develop solutions. Since I had spent a year volunteering in the organization, engaging in their youth-led work, I was able to develop research questions that strongly aligned to prior work of the organization. This likely affected the degree to which the youth co-researchers were engaged in the process. The following sections illustrate how the Cambodian youth demonstrated resistant capital during the Photovoice process.

\section{Challenging the Assumption that American = White}

The Cambodian co-researchers often spoke about the societal perception that Americans are White, monolingual English speakers, and how they are constantly assumed to be non-American because of the color of their skin. They also spoke about the pressure they and their parents face to learn English and become "American" like everyone else, and about the resulting intergenerational communication issues that resulted. In the first round of photography, which was focused on primary language in use, the youth decided to focus on English since it is the language they use most often and most comfortably. In discussing what the focus of their photos might be in this round, they kept associating the English language with American culture or their American side, which they also seemed to associate with Whiteness. In one of our earlier sessions (April 8, 2015), Drake reflected on this topic, recalling a time when a teacher had asked him and his classmates to talk about "who are you, and like, what's your culture":

And this one Spanish kid who was like, oh, yeah, I'm, I forgot his name, he's like, I'm American, not nothing else, I'm American cause I was born, born in America. And I was like, what are you talking about, you're not White. And then, like, the realization, like, yo, it was to the point where you know, when I was thinking about AmeriCANs, I was thinking about White people, and it's ridiculous how your reaction is to think that.

This excerpt shows Drake's own realization that societal messages about Americans being White people had become the norm in his own mind. He had thought of himself as non-American due to his darker skin and likely also his Cambodian cultural practices, which do not fit into the White, 
Euro-American "norm." The example he shares of the "Spanish kid" shows that this particular kid seems to have internalized these societal messages, choosing to "engage in self-defeating or conformist strategies that feed back into the system of subordination" (Yosso, 2005). With such a reaction, it seems likely that he had experienced racial or linguistic microaggressions that had devalued his linguistic and cultural knowledge growing up (Solórzano, 1998). On the one hand, Drake is recognizing his tendency to essentialize Americans as White people, but on the other, he is essentializing Spanish-speakers as Spanish, when most likely this particular "Spanish kid" who had darker skin was actually from a Latin American country with its own unique cultural and linguistic practices, distinct from those of Spain.

In a later session, Drake shared another story, where he seemed to be struggling with this idea of Americans being White. He explained that he has seen a guy with a shirt that read, "I was a proud American. I WAS a proud American. With proud in quotation marks." He went on to say, "he was either sick and tired, you know, of like, Black people rebellion, or ... or he can be sick and tired of like, the way the system works, you know?" In debating how to interpret the man's shirt, Drake used his resistant capital and knowledge of the system and race-based reactions. In speculating that this man was tired of "Black people rebellion," he seemed to say that the man may have been upset about People of Color in the United States resisting the status quo of White privilege. In speculating that the man may have been sick and tired of how the system works, he seemed to suggest that the man felt frustrated with the economic system privileging corporate interests over people. In subsequent sessions, the Cambodian youth continued to explore these racial assumptions and divisions in their community, citing many examples that seemed to be enforcing this subconscious assumption that Americans are White people.

\section{Explaining Racial Divisions and the Policing of the Cambodian Community}

In their explanations of their photos and reflection on their experiences growing up in Eagle City, the Cambodian co-researchers spoke about the racial divides that exist in their community. Reptar spoke about community racial divisions in his explanation of his photo of a loft-style apartment building (Figure 1).

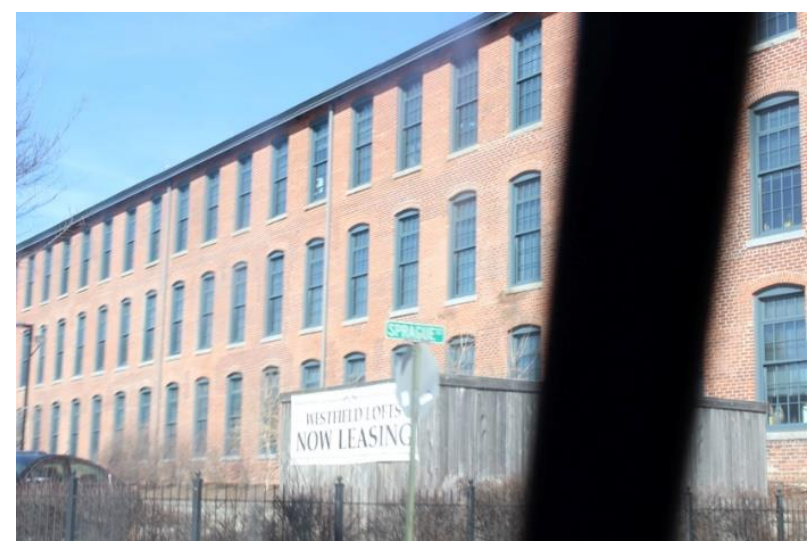

Figure 1. Where you would find a lot of White people. Photograph by Reptar.

Reptar explains that he took this picture while driving around Ace's neighborhood and that it is a "a picture where you would find a lot of White people," to which Ace replies, "It's a really nice 
loft." Reptar goes on to explain, "But, um Asians probably, you'd find in a three-decker apartment building, mmhm, or in a project." I ask if those are nearby, and Ace explains,

Um, so, there's like, the really American side of the West Side, and there's like the ghetto side of the West Side. So like the American side is more towards, like, the park or the armory.

She and Reptar explain that many of the homes on the "American" side of the neighborhood are Victorian style and/or considered historical and well-built and well-maintained. While mainly Hispanic and Southeast Asian families, including many Cambodians, live on the "ghetto" side where Ace also lives. Ace spoke about how she began to recognize this division in relation to her perceptions about violence in the community:

Ace: I was always kind of used to it. I mean, we grew up in Sandville, but, we didn't see that much, like ...

Reptar: You didn't.

Ace: Well, yeah. I mean, I saw the occasional, like fights and shoot-outs, but it was always normal to me. I mean, I thought that that was what happened. But, growing up, I realized what, that's not what you're supposed to see. At six years old. (April 8, 2015)

Ace notes how she began to realize that persistent violence is not a healthy, normal childhood experience. As she aged and gained more experience, she developed the awareness of the stark racial and ethnic divisions in Eagle City that seemed to be connected to safety and violence as well. She seems to say here that in Sandville and her current neighborhood on the West Side, where folks lived in subsidized housing or in run-down apartments, violence was more prevalent. She realized that her family was resettled into the poorest area of the city. Eric Tang (2015) suggests that this was the case for many Cambodian families in Eagle City, as well as in other northeastern cities. In stating that "that's not what you're supposed to see. At six years old," Ace recognizes that this violence is not normal and perhaps only exists in their and other raciallysegregated neighborhoods.

They also associated these racial divisions in the community with policing and criminalization of Southeast Asian folks and law enforcement's perception of them as nonAmerican. In presenting a photo of police cars and emergency service vehicles parked in a lot in their neighborhood, Reptar explained, "I took this photo because, Cambodians, they do not like police." When I asked why not, he responded, "Because, um, we do not understand them. We understand that they're there for safety, but most of the time, it's not for our, our safety. It's for the safety of an American." He seemed to allude to the fact that his community is profiled and policed, rather than protected by the police. Later he added, "Yeah, I'm not American to a police officer," and went on to explain that officers have asked him where he is from and spoken to him in Spanish, despite his statement that he was born in the United States (April 8, 2015, p. 14). Reptar returns to Drake's idea that Americans are White people, and that all others are perpetually foreign. By othering him as non-American, the police render him less human, thus less worthy of protection. This perspective on the role of the police, as well as the discourse he uses, is something that Reptar likely developed at ECYA. I imagine that as a teenager when he first joined ECYA, he had felt frustrated about the unfair treatment he had received from the police. Later through 
workshops on the history of the policy that he both attended and later facilitated at ECYA, he gained the skills and vocabulary necessary to talk about his experience.

Ace offers a response to law enforcement in explaining her photo of the Cambodian Buddhist temple near her home (Figure 2).

Um, the Southeast Asian community is pushed to the side very often taken for granted. Since we're profiled so often about the gangs that are formed, about the convicts that are supposedly Southeast Asian, because we're like, these bad people. Um, people don't see our cultural side. The things we grew up with, the way we live, our rituals, what we come from, our traditions. We're casted away, and we're left to be forgotten. Um, what can we do about it? My activist side kind of came out on this question. Um, so, uh, allow us to be a part of the community, and let law enforcement know that we're not just full of gang members and convicts, that we're a lot more than that. Allow them to see that we're not the problem. The way they do their job is the real issue. (May 6, 2015)

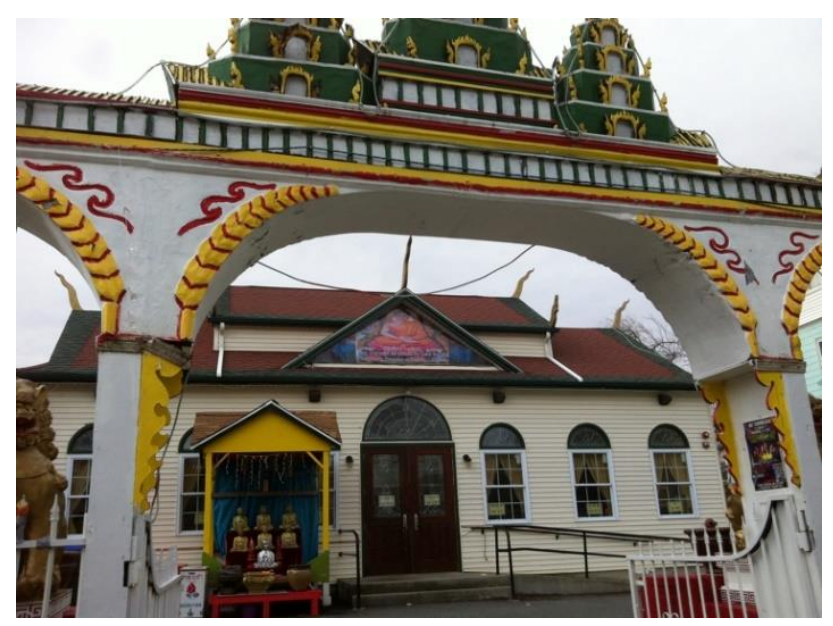

Figure 2. Our place of worship is no different than yours. Photograph by Ace.

Ace revisits the idea of the Southeast Asian community being profiled and assumed dangerous here. By pointing out these injustices in the way they are treated by law enforcement and by naming how they came about, Ace demonstrates her resistant capital and deep understanding of the systemic discrimination at play. She also draws attention to how the criminalization of subgroups within the community affects the community at-large. In stating, "The way they do their job is the real issue," she makes the connection to the source of violence being that of police officers. This dovetails with Freire's (1970) theory that, "Never in history has violence been initiated by the oppressed. Violence is initiated by those who oppress, who exploit, who fail to recognize others as persons - not by those who are oppressed, exploited, and unrecognized" (p. 55). By bringing out her "activist side" and pointing out that the Southeast Asian community is a lot more than "gang members and convicts," Ace suggests that the police currently operate with a deficit view of her culture. Reading more deeply into this, she also suggests that what is needed is a change in the practice of policing to an assets-based view, one that operates from a place of respect for and understanding of the various cultures in the community. If the police officers that had stopped Reptar had been educated about diverse cultures, histories, and 
perspectives in school in their professional training, they would likely have approached him with greater respect, rather than automatically assuming him to be alien.

This frustration with the lack of cultural recognition in the community surfaced in many of our discussions, including those about school. The co-researchers hypothesized that the absence of Cambodian, and larger Southeast Asian, histories and cultures in the curriculum may be a contributing factor to the divides in the community, which I examine further in the subsequent section.

\section{What about our human rights? Putting Cambodian History into the Curriculum}

The co-researchers exhibited a deep frustration for the denial of access to their own history in the school curriculum. Often in our conversations, someone would speak about how the only reference to Cambodia in school was in the brief mention of the Vietnam War, if that was even covered at all. They would also point to the issues inherent in naming it the Vietnam War, as opposed to, for example, the American War in Southeast Asia. They demonstrated their resistant capital, not only in their recognition of the absence of Cambodian history in the curriculum, the importance of naming to perception, but also in their suggestions for how it could and should fit.

In one of our first discussions, Foster K. expressed her frustration in having to be the one doing the educating:

Like when I'm in school, I'll bring up the Khmer Rouge and people just be like, what? And I be like, now I gotta educate you and everything, like. And then when you tell them about the Vietnam War they'll be like, Ooooh (March 18, 2015).

Ace goes on to offer her thoughts about how the war is named:

I think that's the thing about it though. It's like, since it was called the Vietnam War, like, everybody thinks that it just, like, affected Vietnam, and they don't realize that the surrounding countries were just as ambushed and just as hurt as Vietnam. I don't know, I think it's the way America frames it. Like we should just forget about the rest of Southeast Asia" (March 18, 2015).

Foster K. and Ace exhibit their resistant capital here, in how they articulate why Khmer people work to preserve their culture in their community and also how the history of the Vietnam War is framed in the United States history books. In calling attention to the naming of the war in such a way, they recognize that it is framed and taught from a White Euro-American perspective, thus positioning all other experiences as insignificant. By saying that America's framing of the war in such a way implies that "we should forget about the rest of Southeast Asia," Ace seems to suggest that the authors of the United States history curricula intentionally silence the experiences of the Cambodians, Laotians, and Hmong in the war.

In a later session (April 15, 2015), Drake noted that the history curriculum has not changed in generations, and expressed his frustration with only learning about World War I and World War II, and using the same materials as prior generations. Ace agreed, stating, "I hate it too. You're only teaching us about one race." When he learned from the other co-researchers about the current history course options offered in Eagle City high schools, Reptar remarked, "What, what, um, blows my mind is that, it's just the United States, Europe, and then everything else bunched into 
World. That's White supremacy at its best" (May 13, 2015). Reptar calls out the ethnocentrism of the United States history curricula again here, moving one step further by naming it as a result of White supremacist influences. His recognition of this racist framing of the United States and world history may stem from his own experience as a Person of Color in a society that privileges the experiences of folks of White European middle-class background. With his perspective as someone whose home language and culture were not present in school or society, he has gained the resistant capital necessary to recognize that the teaching of the histories of Peoples of Color would be a potential threat to White the United States/European superiority.

Linda also reflected on the way that history is currently taught, suggesting that the students would just forget about it later (April 15, 2015). She then expanded on this, noting the presence, or absence, of specific cultures in the curriculum:

Linda: Like, it's, even besides like history, like English, like, we're learning about cultures, and like, what cultures are and everything, but it's like, I haven't heard anything about Cambodia, like their culture like any other different culture, except for like Africa's culture, Chinese culture, Indian culture. Cause like, they're like, broad cultures, and it's like, we did projects, well, presentations, like, um, a while back, and it was like only on countries in Africa. And it's like, and it was like, about their culture and how their, like, human rights were like, violated, and everything.

Ace: What about our human rights?

Drake: Human rights

Linda: It's like, they shouldn't do that. We should actually choose our own country. Like I would've, I would definitely, like represent Cambodia, present it, everything

Ace: Yeah

Linda: Like show how their human rights are, like, violated in Cambodia, and like, it's like, it's broad. (April 15, 2015).

Linda is keenly aware of the essentialization of distinct cultures into larger, homogenizing ones in the current curriculum. By calling attention to her teacher's choice to focus an assignment on human rights on Africa, she calls out the essentialization of the diverse ethnicities, languages, and cultures of the continent into one homogenous whole. She also seems to call out the bias inherent in the assignment that suggests that the continent is the primary site of human rights violations in the world. It is clear that Linda, as well as the others, would like to really learn and dig deep into a topic, and to be allowed to explore the human rights topic by looking at their own cultures and histories that are so often silenced in the curriculum. CRT deliberately provides the space for typically silenced voices, experiences, and knowledges to be heard. Having the space provided by ECYA, in which to explore these topics among peers and adults, allows the youth to develop the agency and critical consciousness necessary for the development of resistant capital. The youth also suggested that it is possible to do this in school in their recommendation that Eagle City Public Schools implement Ethnic Studies courses reflecting the demographics of the city.

\section{Language Taught in School = Language Spoken by White Folks}

Not only did the youth co-researchers call for the inclusion of Ethnic Studies in the school curriculum, but they also called for the option to develop their Khmer in school. In developing the recommendations for ECPS, they called for Khmer courses, as well as for other languages that 
reflect the demographics of the community, exhibiting their resistant capital in calling attention to the inequities present in the current system. Foster K. and Drake, in particular, chose to photograph materials used in their Spanish (Figure 4) and French (Figure 5) classes, respectively, to make a more impactful statement at the gallery walk.

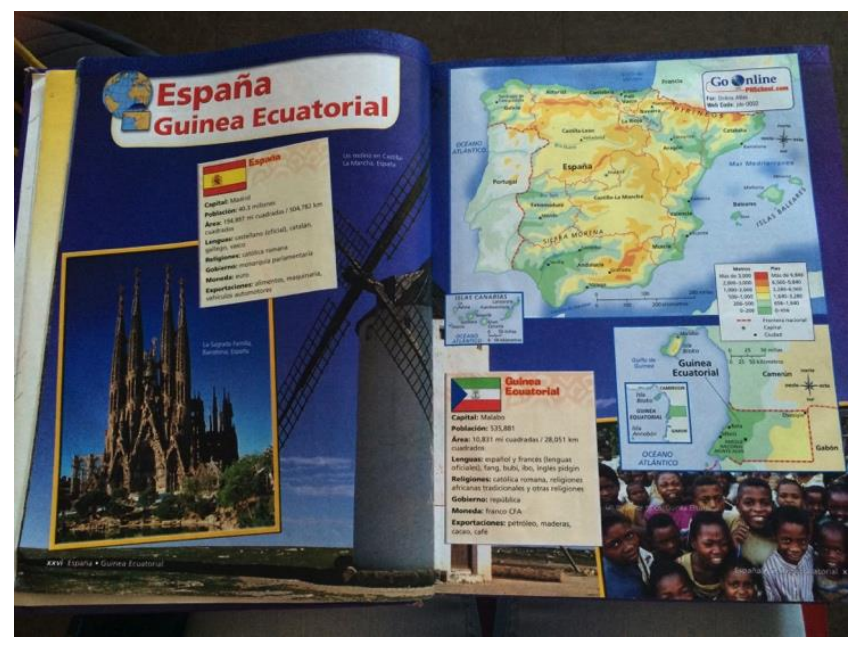

Figure 3. Learning Spanish Level 2. Photograph by Foster K.

While the caption she chose is rather literal, in writing her reasons for taking this photo (Figure 3), Foster K. explained, "This is a strength because learning a new language can be fun. This is a concern because I can also be losing my Khmer skills." In response to the question, "What can we do about it?" she offered, "Can at least try to have some sort of Khmer classes or some Cambodian history/course as well as other nationalities/ethnicities to be fair?" Foster K. sees the value in learning multiple languages, but challenges what is currently offered in ECPS in suggesting that the district alter their language and history course offerings to honor the diversity of ethnicities represented. The reader can sense her frustration in the way she words her recommendation, using the phrases, "Can at least try" and "to be fair." She seems to imply here that from her perspective ECPS is not trying to "be fair" and include all of the various ethnic groups at the decision-making table, while also recognizing that this may be difficult for ECPS to do.

In his written response to his photo in Figure 4 Drake explained, "We only have three languages in the typical Eagle City Public School curriculum which is Spanish, French, and Italian." He went on to write, "This situation concerns me a lot because we are only learning that were spoken by White folks ... could [be] degrading for foreign cultures." Although Spanish in EC is spoken mainly by Black and Brown students now, Drake seems to recognize here that the Spanish taught in school is the colonial language of Spain. In response to this, he suggested that ECPS:

Give more foreign language choices for students. Ex. Khmer so Cambodians that don't know their language well can be able to learn their own language and speak to their folks that do not know how to speak English. 
Drake's response to his photo expands on Foster K.'s comment about her own Khmer language loss by making the connection between language loss and intergenerational communication issues. His caption, "Why can't I learn about my country and my language?" is a demonstration of his resistant capital, implying that the educational system currently suppresses his language and culture, while privileging the languages of White Europeans, or as Reptar explained, "Europeans control the world" (May 6, 2015). Reptar reinforces the idea Drake alluded to previously that the Spanish that is taught in school is that of White Europeans. When I asked if there are Spanish classes for Spanish-speakers, the youth replied in the negative. They explained that students are just placed in a higher level, giving them access to AP classes sooner, but not necessarily differentiating instruction to meet them where they are linguistically and culturally.

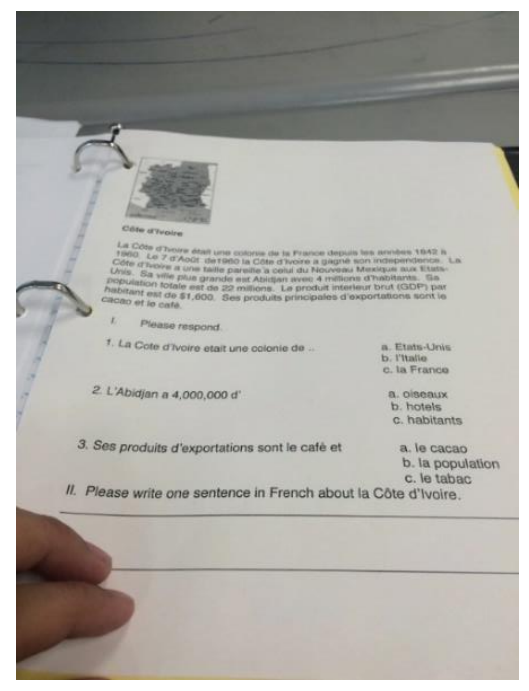

Figure 4. Why can't I learn about my country and my language? Photograph by Drake

Linda chose to make the argument about the need for Khmer language classes from a different angle, presenting a photo of a hand-written sign in Khmer that hangs in the office of their organization that no one, not even their director, can read (Figure 5).

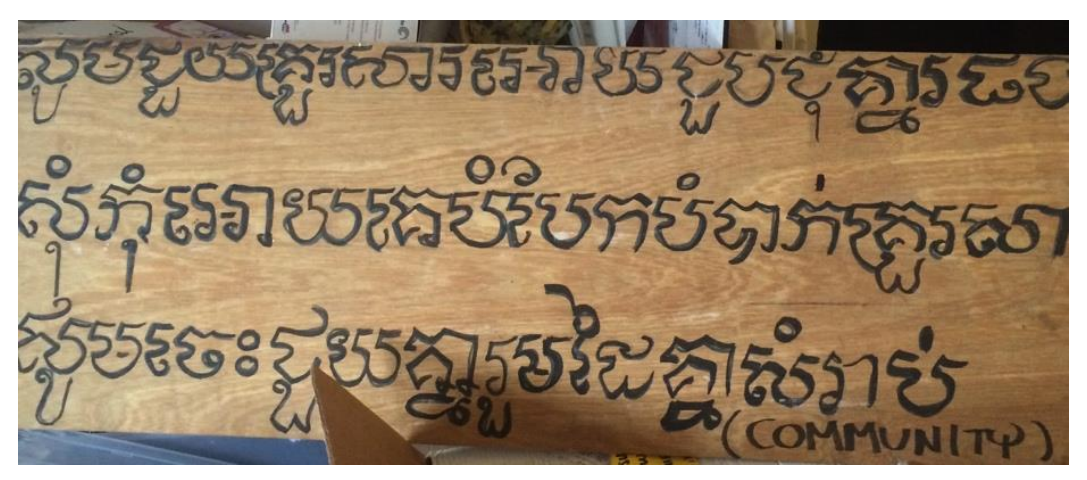

Figure 5. If you are Cambodian, do you know what this says? Photograph by Linda. 
Linda also wrote and spoke about the loss of Khmer reading and writing ability fading over time, suggesting in her written response that, "This situation exists because everything taught in public schools are English, and not our own language." Because of the overwhelming influence of English, the youth would often speak about feeling ashamed to speak Khmer in school growing up for fear of being teased by their peers and from their experience in being misunderstood by teachers. As they entered adolescence, they began to long for improved Khmer ability. Linda spoke most often about her journey to overcome the silencing of her Khmer language, offering examples of how she would ask for help from others in learning Khmer, and how she now tries to speak with her mother in Khmer as a way to reclaim the language for future generations.

\section{Discussion}

I have attempted to illustrate how the youth co-researchers demonstrated their agency through this study, and how the Photovoice process might be used as a tool to recognize and support resistant capital among linguistically-minoritized youth. By reflecting on the demonstration of resistant capital by the Cambodian co-researchers who participated in this study, I found that a variety of demographic and contextual factors affected their use of resistant capital. The Photovoice process allowed youth the space to critically reflect on the linguistic and social strengths and concerns, but could have been more effective in developing resistant capital with more time, as well as the integration of critical study of their history and of language education policies.

The examples of my Cambodian co-researchers' analyses of systemic injustices show that they have developed the critical consciousness necessary in developing resistant capital. Through their participation in ECYA, the Cambodian youth have received and facilitated trainings designed to allow youth to frame personal issues as political and to work collaboratively with others in the community to address these issues. Holding our meetings in the ECYA space, where they felt a sense of ownership, community responsibility, and freedom to speak their minds, seemed to allow for more candid conversations about issues related to language affecting them and their community. In this space, they were comfortable addressing me by my first name and seemed to see me truly as a collaborator or facilitator, rather than an authority figure. Creating a similar level of comfort and trust in schools may be difficult, but with collective commitment may be possible in order to provide space for the development of resistant capital among other linguisticallyminoritized youth, as well as with White, European-background youth who have also been denied a critical exploration of their own histories.

How might schools facilitate the development of resistant capital among young people? What could it look like to employ a CRT perspective in the planning of a history/social studies curriculum? How might this look differently with different populations?

With adequate time, a welcoming, safe space, and a trusted educator facilitator, the Photovoice process could allow for the development of resistant capital among youth coresearchers in school settings. The Photovoice project could be integrated into a combined English/Social Studies block, allowing time to first develop an equal relationship between teacher and students and establish trust, and to engage in critical exploration of the participants' histories. Developing a trusting relationship where the youth see the adult researcher or teacher as more of an equal would likely provide the emotional space for the youth to share their more personal ideas and experiences. The dialogue about issues the youth identify in the community could be supplemented with exploration of the related historical and political context, as it applies to the particular group. 
For example, educators and learners could explore the histories of migration to and from the United States centering their own experiences as a starting point. This would eventually include the exploration of the history of the relationship between Indigenous and European-background groups in countries of origin, the United States' role in those countries historically and today, and the relationship between these factors and migration. The teacher/researcher would not need to have expertise in all of the particular histories, but could facilitate the process of having the youth research their histories and to also identify community leaders and organizations that may be able to share historical and contextual information. The critical exploration of history could be complemented with a Photovoice project focused on an issue identified by the particular group of youth co-researchers. In order to have a clearer vision of the goal of the Photovoice process, it would also be important to select a target group of stakeholders earlier in the process to allow for sufficient time for sending invitations and for the development and revision of the recommendations prior to the final photo gallery walk(s). Holding just one photo gallery walk seems insufficient for effecting policy change, however with the policy recommendations set and photos mounted, the event could be held in various locations to reach a greater audience. The youth co-researchers could also be engaged in the development of a longer-term campaign to implement their recommendations that extends beyond the Photovoice project through a school-related or other community organization, which would certainly further extend their resistant capital.

\section{Notes.}

1. Data source not included to maintain the anonymity of the youth.

2. Pseudonyms used to protect the anonymity of the participants.

\section{References}

Bourdieu, P. (1986). The forms of capital. In J. Richardson (Ed.) Handbook of theory and research for the sociology of education (pp. 241-258). New York, NY: Greenwood.

Bourdieu, P., \& Passeron, J.-C. (1977). Reproduction in education, society and culture. London, UK: Sage Publications, Inc.

Cammarota, J. (2004). The gendered and racialized pathways of Latina and Latino youth: Different struggles, different resistances in the urban context. Anthropology \& Education Quarterly, 35(1), 53-74.

Cammarota, J., \& Fine, M. (2008). Revolutionizing education: Youth participatory action research in motion. New York, NY: Routledge.

Chang, R. (1999). Disoriented: Asian Americans, law, and the nation-state. New York, NY: New York University Press.

Chhuon, V. (2014). "I'm Khmer and I'm not a gangster!": The problematization of Cambodian male youth in U.S. schools. International Journal of Qualitative Studies in Education, 27(2), 233-250.

Chhuon, V. \& Hudley, C. (2010). Asian American ethnic options: How Cambodian students negotiate ethnic identities in a U.S. urban school. Anthropology \& Education Quarterly, 41(4), 341-359.

Delgado, R. \& Stefancic, J. (2001). Critical race theory: An introduction. New York, NY: New York University Press. 
Delgado Bernal, D. (2002). Critical race theory, Latino critical theory, and critical raced-gendered epistemologies: Recognizing students of color as holders and creators of knowledge. Qualitative Inquiry, 8(1), 105-126.

Feuerherm, E.M. \& Ramanathan, V. (2016). Refugee resettlement in the United States: Language, policy, pedagogy. Bristol, UK: Multilingual Matters.

Freire, P. (1970). Pedagogy of the oppressed. New York, NY: Continuum.

García, O. (2009). Bilingual education in the $21^{\text {st }}$ Century: A global perspective. Malden, MA: Wiley-Blackwell.

Gignoux, A. (2009). Survey of demographic and self-identification information for heritage learners of Mexican descent. Los Angeles, CA: National Heritage Resource Center. Retrieved from: http://nhlrc.ucla.edu/data/questionnaires.asp

Ginwright, S., \& Cammarota, J. (2007). Youth activism in the urban community: Learning critical civic praxis within community organizations. International Journal of Qualitative Studies in Education, 20(6), 693-710.

Greenwood, D. J. \& Levin, M. (2007). Introduction to action research: Social research for social change. Thousand Oaks, CA: Sage Publications.

Herr, K. \& Anderson, G. (2015). The action research dissertation:A guide for students and faculty. Thousand Oaks, CA: Sage Publications.

Ladson-Billings, G. (1998). Just what is critical race theory and what's it doing in a nice field like education? International Journal of Qualitative Studies in Education, 11(1), 7-24.

Mohanty, S. P. (2000). The epistemic status of cultural identity. In P. M. L. Moya \& R. HamesGarcía (Eds.), Reclaiming identity: Realist theory and the predicament of postmodernism (pp. 29-66). Berkeley, CA: University of California Press.

Moll, L. C., Amanti, C., Neff, D., \& Gonzalez, N. (1992). Funds of knowledge for teaching: Using a qualitative approach to connect homes and classrooms. Theory Into Practices, 31(2), $132-141$.

Montrul, S. (2012). Bilingual background questionnaire for Spanish/English speakers. Los Angeles, CA: National Heritage Resource Center. Retrieved from: http://www.nhlrc.ucla.edu/data/questionnaires.asp.

Ngo, B., \& Lee, S. J. (2007). Complicating the image of model minority success: A review of Southeast Asian American education. Review of Educational Research, 77(4), 415-453.

Nygreen, K. (2009-2010). Critical dilemmas in participatory research: Toward a new theory of engaged research for social change. Social Justice, 36(4), 14-35.

Papa, E. (2018). Using photovoice with Cambodian and Guatemalan youth to explore the relationships and tensions among home, community, and school linguistic and social practices and uncover community cultural wealth. In S. Shapiro, R. Farrelly, and M.J. Curry (Eds.), Educating refugee-background students: Critical issues and dynamic Contexts (pp. 159-176). Bristol, UK: Multilingual Matters.

Patton, M. Q. (2002). Qualitative research and evaluation methods. Thousand Oaks, CA: Sage Publications, Inc.

Smith-Hefner, N. J. (1993). Education, gender, and generational conflict among Khmer refugees. Anthropology \& Education Quarterly, 24(2), 135-158.

Solórzano, D. G. (1998). Critical race theory, race and gender micro-aggressions, and the experience of Chicana and Chicano scholars. International Journal of Qualitative Studies in Education, 11(1), 121-136. 
Tang, E. (2015). Unsettled: Cambodian refugees in the New York city hyperghetto. Philadelphia, PA: Temple University Press.

Tang, K. \& Kao, D. (2012). Ethnicity, gender, and the education of Cambodian American students in an urban high school. Journal of Southeast Asian American Education \& Advancement, $7,1-22$.

Wallitt, R. (2008). Cambodian invisibility: Students lost between the "achievement gap" and the "model minority." Multicultural Perspectives, 10(1), 3-9.

Wang, C. (2006). Youth participation in Photovoice as a strategy for community change. Journal of Community Practice, 14(1/2), 147-161.

Wang, C., \& Burris, M. A. (1997). Photovoice: Concept, methodology, and use for participatory needs assessment. Health Education \& Behavior, 24(3), 369-387.

Yosso, T. J. (2005). Whose culture has capital? A critical race theory discussion of community cultural wealth. Race Ethnicity and Education, 8(1), 69-91.

Yosso, T. J., \& García, D. G. (2007). "This is no slum!”: A critical race theory analysis of community cultural wealth in culture clash's Chavez Ravine. Aztlán: A Journal of Chicano Studies, 32(1), 145-180.

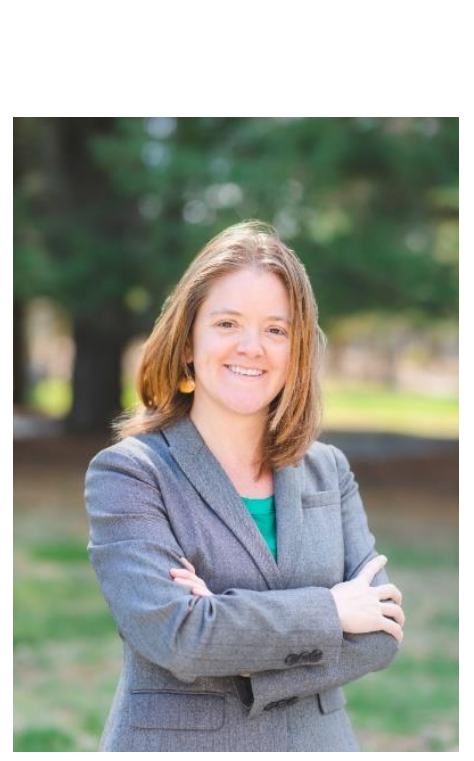

\begin{abstract}
About the Author
Erin L. Papa, Ph.D., is Assistant Professor of Educational Studies and Coordinator of the World Languages Education Program at Rhode Island College. She has taught multilingual learners in K-16 in the United States, China, and Australia in school and community spaces and previously worked for the Chinese Flagship and International Engineering Programs at the University of Rhode Island. Her research interests include heritage language learners, critical race theory, and language education policy and planning. Erin also serves as Advocacy Chair of the Rhode Island Foreign Language Association (RIFLA) and is working with other community activists to develop and lead the Coalition for a Multilingual Rhode Island.
\end{abstract}




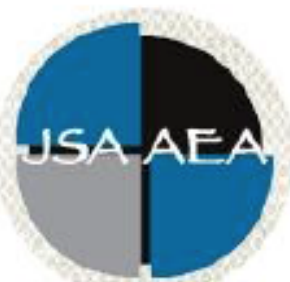

Vol.14 Iss.1 (2019)

\section{Journal of Southeast Asian American Education and Advancement}

\author{
Editor \\ Dr. Wayne E. Wright \\ Purdue University \\ Associate Editors \\ Dr. Chhany Sak-Humphry \\ University of Hawaii at Manoa \\ Dr. Phitsamay Sychitkokhong Uy \\ University of Massachusetts, Lowell \\ Book Review Editor \\ Dr. Vichet Chhuon \\ University of Minnesota \\ Creative Works Editor \\ Bryan Thao Worra \\ Lao Assistance Center \\ Journal Manager \\ Fang Gao \\ Purdue University
}

Editorial Review Board

\author{
Dr. Steve Arounsack \\ California State University, Stanislaus \\ Dr. Sovicheth Boun \\ Salem State University \\ Dr. Virak Chan \\ Purdue University \\ Dr. Loan Dao \\ University of Massachusetts Boston
}

\author{
Dr. Carl L. Bankston III \\ Tulane University \\ Dr. Phala Chea \\ Lowell Public Schools \\ Dr. George Chigas \\ University of Massachusetts, Lowell \\ Dr. Hien Duc Do \\ San Jose State University
}




\author{
Dr. Changming Duan \\ University of Missouri-Kansas City \\ Dr. Sothy Eng \\ Lehigh University \\ Dr. Vincent K. Her \\ University of Wisconsin, Eau Claire \\ Dr. Peter Nien-Chu Kiang \\ University of Massachusetts, Boston \\ Dr. Kevin K. Kumashiro \\ University of Illinois, Chicago \\ Dr. Ha Lam \\ Independent Scholar \\ Dr. Jonathan H. X. Lee \\ San Francisco State University \\ Dr. Monirith Ly \\ Royal University of Phnom Penh \\ Dr. Bic Ngo \\ University of Minnesota \\ Dr. Leakhena Nou \\ California State University, Long Beach \\ Dr. Mark Pfeifer \\ SUNY Institute of Technology \\ Dr. Loan T. Phan \\ University of New Hampshire \\ Dr. Karen Quintiliani \\ California State University, Long Beach \\ Dr. Angela Reyes \\ Hunter College \\ The City University of New York \\ Dr. Fay Shin \\ California State University, Long Beach \\ Dr. Christine Su \\ College of San Mateo \\ Dr. Alisia Tran \\ Arizona State University \\ Dr. Khatharya Um \\ University of California, Berkeley \\ Dr. Kim Tran \\ University of California, Los Angeles, \\ Glendale Community College \\ Dr. Molly Wiebie \\ The University of Texas at Austin
}

Dr. Sophal Ear

Occidental College

Dr. Jeremy Hein

University of Wisconsin, Eau Claire

Dr. Nancy H. Hornberger

University of Pennsylvania

Dr. Peter Tan Keo

New York University

Dr. Yvonne Kwan

San Jose State University

Dr. Ravy Lao

California State University, Los Angeles

Dr. Stacey Lee

University of Wisconsin, Madison

Dr. Sue Needham

California State University, Dominguez Hills

Dr. Max Niedzwiecki

Daylight Consulting Group

Dr. Clara Park

California State University, Northridge

Dr. Giang Pham

University of Massachusetts Amherst

Dr. Malaphone Phommasa

University of Clifornia Santa Barbara

Dr. Kalyani Rai

University of Wisconsin-Milwaukee

Dr. Cathy J. Schlund-Vials

University of Connecticut, Storrs

Dr. Nancy J. Smith-Hefner

Boston University

Dr. Yer J. Thao

Portland State University

Dr. Monica M. Trieu

Purdue University

Dr. Silvy Un

Saint Paul Public Schools

Dr. Linda Trinh Vo

University of California, Irvine

Dr. Yang Sao Xiong

The University of Wisconsin-Madison

Dr. Zha Blong Xiong

University of Minnesota 


\section{Doctoral Student Editorial Review Board}

\author{
Linh Dang \\ University of Rochester \\ My-Lan Huynh \\ California State University East Bay \\ Jacqueline Mac \\ Indiana University \\ Hoa Nha Nguyen \\ Boston College \\ Thien-Huong Ninh \\ University of Southern California \\ Latana Thaviseth \\ University of California Los Angeles \\ Mai Vang \\ University of Massachusetts Boston \\ Soua Xiong \\ San Diego State University \\ Claremont Graduate University
}

\author{
Annie BichLoan Duong \\ San Joaquin County Office of Education \\ Vanessa Sovanika Na \\ University of California SanDiego \\ Dung Minh Mao \\ University of Minnesota \\ Khoi Nguyen \\ George Mason University \\ Linda Marie Pheng \\ University of Wisconsin-Madison \\ Krissyvan Truong \\ Claremont Graduate University \\ Melissa Vang \\ San Diego State University
}

